\title{
Experimental and Numerical Investigations of Heat Impact and Flame Heights from Fires in SBI Tests
}

\author{
JIANPING ZHANG, MICHAEL DELICHATSIOS, MATTHIEU COLOBERT, JOHAN HEREID, \\ MARTIN HAGEN and DIMITRIOS BAKIRTZIS \\ FireSERT, Research Institute of Built Environment \\ University of Ulster \\ FireSERT, University of Ulster at Jordanstown, Newtownabbey, BT37 0QB, Northern Ireland
}

\begin{abstract}
This work consists of experimental and numerical investigations of heat impact and flame heights from fires in single burning item (SBI) tests. In the experiments, thin steel plate probes were developed, as an inexpensive and reliable alternative to heat flux gauges, to measure the surface heat flux, whilst flame heights were determined by analyzing the instantaneous images extracted from the videos of the experiments by a CCD camera. The experimental results were subsequently used to assess the accuracy of the CFD code, Fire Dynamics Simulator (FDS), for predictions of the surface heat flux and flame heights. The results indicated that although FDS V4.07 predicts reasonably flame heights, it underpredicts significantly the surface heat flux especially at higher heat release rates. Consequently, sensitivity of the parameters used in the radiation and soot models in FDS was examined.
\end{abstract}

KEYWORDS: single burning item (SBI) tests, steel plate probes, surface heat flux, flame heights, CFD modelling, FDS

\section{INTRODUCTION}

Fires breaking out in corners have been identified as the worst scenario in fire development because in a corner fire less fresh air is entrained into the plume than in an unbounded fire resulting to higher thermal plume temperatures. Moreover, less air entrainment implies less mixing of the flame with ambient air, resulting in an increasing flame height. Consequently, hazards induced by a corner fire could be high concerning the temperature rise of structural elements, ignition and thus flame spread of combustible walls, and the time to flashover etc. Over the last decades, a number of experimental studies of corner fires have been reported in the literature [e.g. 1-7]. These studies generally fall in one of the following three types: a) flame height and plume flow [1-3], b) surface heat flux [5,7], and c) flame spread [4,6]. Of particular interest in this work are the surface heat flux and flame height. The corner fire configuration considered is the well-ventilated single burning item (SBI) test (EN 13823) [8], which serves well as an intermediate bridge linking the full-scale (e.g. the ISO room) tests and the small-scale (e.g. the cone calorimeter) tests.

Surface heat fluxes from fires are usually measured with heat flux gauges; however if one wishes to map the whole surface in question a large number of heat flux gauges are needed which makes conducting experiments of this kind highly costly. Alternatively, researchers of the researchers' group [9,10] have previously developed a type of thin steel plate probes, consisting of a thin steel plate flush mounted in an insulation material. In this work, a similar steel plate probe $(25 \mathrm{~mm}$ wide $\times 25 \mathrm{~mm}$ long $\times 3.2 \mathrm{~mm}$ thick) surrounded by insulation except for the exposed surface has been constructed; the instantaneous temperature of the steel plate is recorded by a Chromel-Alumel thermocouple. The first objective of this work was validation of thin steel plates as an inexpensive and reliable means for measuring heat flux in large-scale fire experiments. In the experiments, a number of steel plate probes were used to measure the surface heat flux on the inert walls. In order to obtain the flame height, a CCD camera was used to record the experiments, each of which lasted approximately 180 seconds. Instantaneous images were extracted from the videos, based on which the flame height was evaluated using an image processing technique [11].

The second objective of this work was to assess the accuracy of the large-eddy simulation (LES) based CFD code, Fire Dynamics Simulator (FDS) V4.07, originally developed at NIST [12], for predictions of the surface heat flux and flame heights. Over the last decade, FDS has been subject to extensive validation exercises for fire-related applications (a detailed list can be found in [12]). These studies generally led to the conclusion that FDS is capable of predicting reasonably well the flow and temperature fields. However, as noted by the code developer [12] for calculations in which the grid cells are on the order of a centimetre and larger, the temperature near the flame surface cannot be relied upon when computing the source term in 
the radiation transport equation, especially because of the fourth power dependence of radiation on temperature. Furthermore, there is no explicit soot model in FDS, and the assumption that the local soot production is proportional to the local fuel burning rate (the proportional factor being soot yield), is also prone to errors in radiation calculations since soot is the dominate species that contributes to radiation in turbulent flames. To bypass these difficulties in radiation and soot modelling, a constant radiative fraction is used in FDS to define the minimum local radiation losses, which are determined experimentally. The third objective of this work was thus to examine the sensitivity of the model parameters in FDS, i.e. radiative fraction and soot yield, on the prediction of the surface heat flux.

This paper consists of experimental procedures and results for surface heat fluxes and flame heights, comparisons of FDS predictions and measurements, and finally a sensitivity study of model parameters concerning radiation and soot modelling in FDS.

\section{EXPERIMENTS}

\section{Experimental instrumentation}

Because the objective was to assess the heat impact and flame heights, instead of combustible materials which are used in standard SBI tests, two inert-wall panels perpendicular to each other were used in this study. These walls are constructed of $25 \mathrm{~mm}$ thick insulation fibreboards (Fiberfax LD) ( $1 \mathrm{~m}$ wide $\times 1.5 \mathrm{~m}$ high). Prior to the tests, the standard propane burner used in the SBI test [8] was calibrated to ensure that it generates the desired burner output. The whole experimental set-up was placed under an extraction hood. The steel plate surface was painted with carbon black to ensure that surface absorptivity is close to one, and a Chromel-Alumel thermocouple was placed at back of the steel plate to record its temperature. In total, 42 steel plate probes (21 on each panel) were used. On each panel, the steel plate probes were located at seven vertical locations $(0.2-1.4 \mathrm{~m}$ above the floor, with an even interval of $0.2 \mathrm{~m})$ and at three lateral locations (3.25, 16.5, and $29 \mathrm{~cm}$ to the corner). A schematic view of the locations of the steel plate probes is shown in Fig. 1. Additionally, two Gardon gauges, denoted by GG1 and GG2 as indicated in Fig. 1, were placed respectively 4cm (centre to centre) away from the steel plate probes L5 and R11.
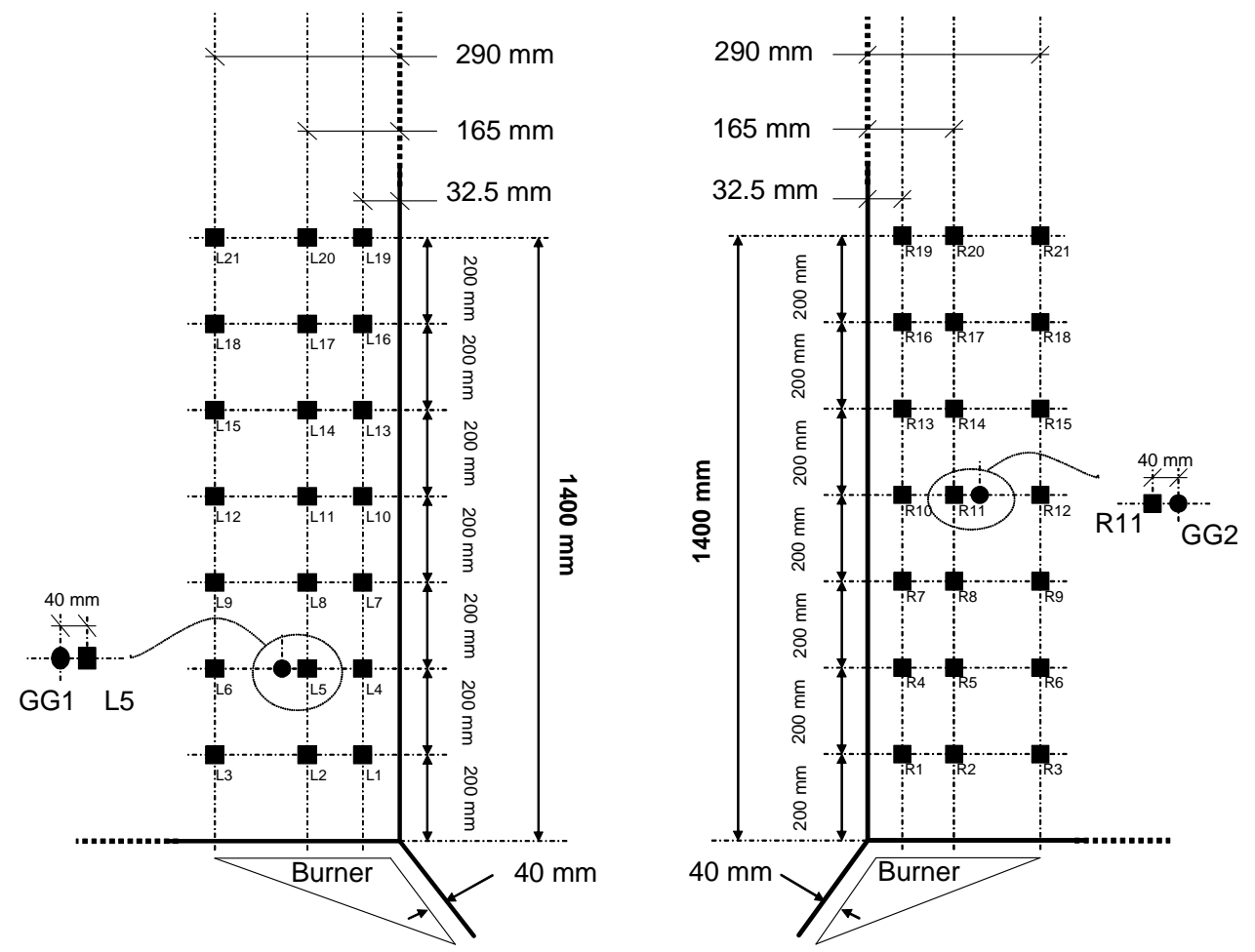

Fig. 1. A schematic view of the locations of the steel plate probes and Gardon gauges. Texts $L$ and $R$ indicate left and right panels respectively, and numbers indicate the locations of the probes. 
For the measurements of the surface heat flux, three HRRs, i.e. 30, 45 and $60 \mathrm{~kW}$, were used. At each HRR level, three repetitive tests were conducted under the same test conditions, and the final results presented were taken as the average of these three tests. To determine the flame height, seven HRRs, i.e. 15, 25, 30, 35, 45, 55 and $60 \mathrm{~kW}$, were used, and all the experiments were video-recorded using a CCD camera (JVC KY-F55B) for approximately 180 seconds.

\section{Calibration of the steel plate probe in the cone calorimeter}

The steel plate probe was firstly calibrated in the cone calorimeter at known external heat fluxes. Figure 2 compares the storage term in the steel plate probe with the Gardon gauge measurement at the initial stage of a sudden exposure, where the storage term in the steel plate probe is calculated as:

$\dot{q}_{\text {store }}^{\prime \prime}=\rho c \delta d T / d t$

where $\rho$ is the density of steel, $c$ the heat capacity of steel, $\delta$ the thickness of the steel plate, and $d T / d t$ the temperature increase rate of the steel plate measured by the thermocouple.

As shown in Fig. 2, after the heat flux stabilized at 10s or so, the average of the storage term by the steel plate is about $29 \mathrm{~kW} / \mathrm{m}^{2}$, whereas the Gardon gauge measurement has a nearly constant value around $30 \mathrm{~kW} / \mathrm{m}^{2}$. This good agreement is due to the fact that at the early stage of a sudden exposure the temperature of the steel plate is low and thus surface convection and re-radiation losses and conduction heat losses to the insulation are negligible. Calibration results at other heat fluxes showed similar patterns, and the relative differences between the steel plate probes and Gardon gauge measurements were always within $10 \%$. Since in the SBI test the flame establishes in few (2-5) seconds, the approximation using the storage term to represent the surface heat flux should still apply; the validity of this approximation will be further examined by comparison to the Gardon gauges measurements in the SBI tests.

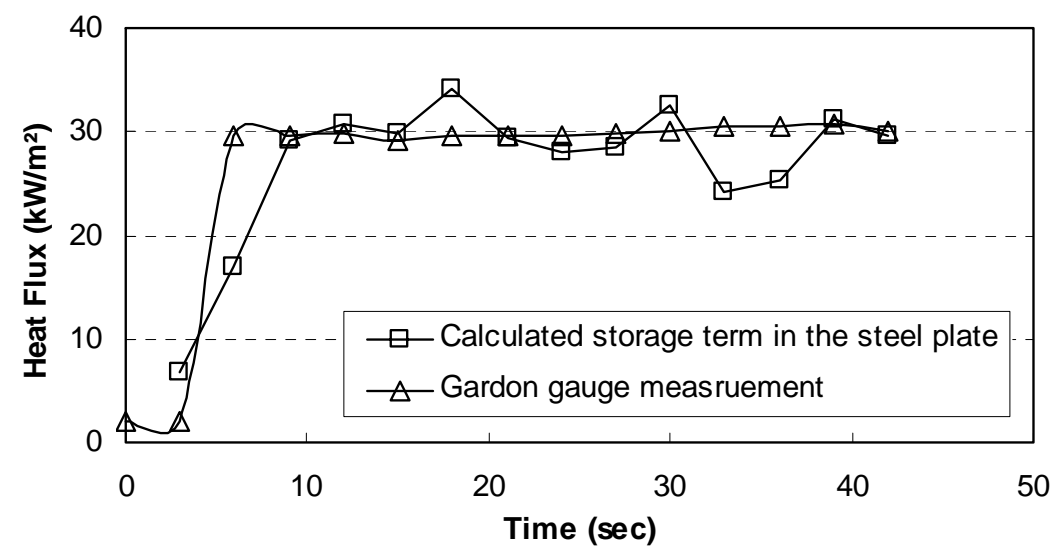

Fig. 2. Comparison of the storage term in the steel plate probe with the Gardon gauge measurement at the initial stage of a sudden exposure in the cone calorimeter.

\section{EXPERIMENTAL RESULTS}

\section{Measurements of the steel plate temperatures}

Figure 3 shows the temperature histories recorded by the thermocouples for one of the tests at $45 \mathrm{~kW}$. The steel plate probe tree corresponding to the results in Fig. 3 was located on the right panel and $3.25 \mathrm{~cm}$ to the corner. Although the fire started at 70s, the calculation range was chosen from 90s to 120s (after the flame stabilized). From Fig. 3, it can be observed that the temperature at location R4 ( $0.4 \mathrm{~m}$ above the burner) increases most rapidly indicating the highest heat flux at this location. Furthermore, one can note that the temperatures over the calculation range increase almost linearly with time, implying that the storage terms in the steel plate as defined by Eq. 1 are almost constant. 


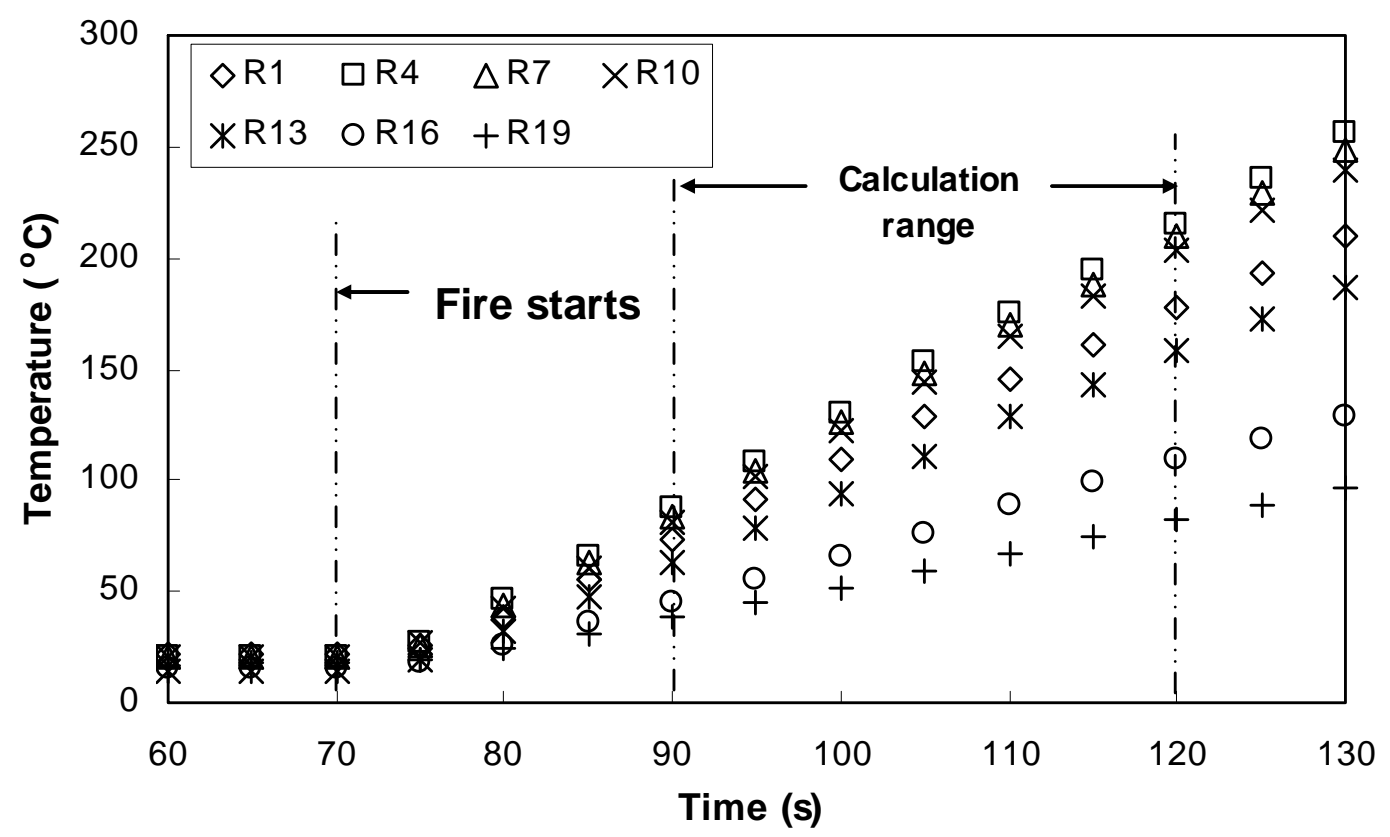

Fig. 3. Temperature histories recorded by the thermocouples for a test at $45 \mathrm{~kW}$. The thermocouple tree was located on the right panel and $3.25 \mathrm{~cm}$ to the corner.

\section{Derived heat fluxes}

From the temperature histories in Fig. 3, the instantaneous storage terms (heat fluxes) were calculated using Eq. 1, based on which the average surface heat fluxes were determined. Figure 4 showing the distribution of the derived surface heat flux at 30,45, and $60 \mathrm{~kW}$ illustrates clearly an important feature of a corner wall fire that the heat flux distribution has a nearly symmetric structure. The heat flux on the right panel is slightly higher than the one on the left panel likely due to the air entrainment effect and the turbulent nature of the flame. The surface heat flux increases with the HRR as expected, and the maximum heat fluxes, found to be located about $0.4 \mathrm{~m}$ above the burner, are 40,55 , and $60 \mathrm{~kW} / \mathrm{m}^{2}$ at 30,45 and $60 \mathrm{~kW}$ respectively. It is also observed that the heat flux isolines in Fig. 4 are more or less parallel to the corner centerline but the heat flux decreases quickly toward the edge of the plume due to air entrainment.

In Table 1, the measurements of the steel plate probes (L5 and R11) are compared to those by the Gardon gauges (GG1 and GG2). The Gardon gauge measurements are systematically lower than the ones by the steel plate probes because the Gardon gauges were located $4 \mathrm{~cm}$ further away from the corner than the steel plate probes compared (i.e. GG1 compared to L5, and GG2 to R11). A simple linear interpolation of the steel plate probes results shows a better agreement between the two sets of data. The average error of the measurements by the steel plate probes in comparison to the ones by the Gardon gauges is around 15\%, which is slightly larger than the one found in the cone calorimeter tests.

Table 1. Comparison of the steel plate probe and Gardon gauge measurements.

\begin{tabular}{c|c|ccc}
\hline & Gauges No & $30 \mathrm{~kW}$ & $45 \mathrm{~kW}$ & $60 \mathrm{~kW}$ \\
\hline & L5 & 16.8 & 21.5 & 30.2 \\
\multirow{3}{*}{ Heat flux $\left(\mathrm{kW} / \mathrm{m}^{2}\right)$} & GG1 & 11.0 & 17.2 & 20.3 \\
& Interpolation (L5 and L6) & 13.5 & 17.7 & 23.7 \\
\cline { 2 - 5 } & R11 & 12.2 & 21.8 & 25.9 \\
& GG2 & 5.6 & 12.5 & 17.1 \\
& Interpolation (R11 and R12) & 9.7 & 17.5 & 20.8 \\
\hline
\end{tabular}



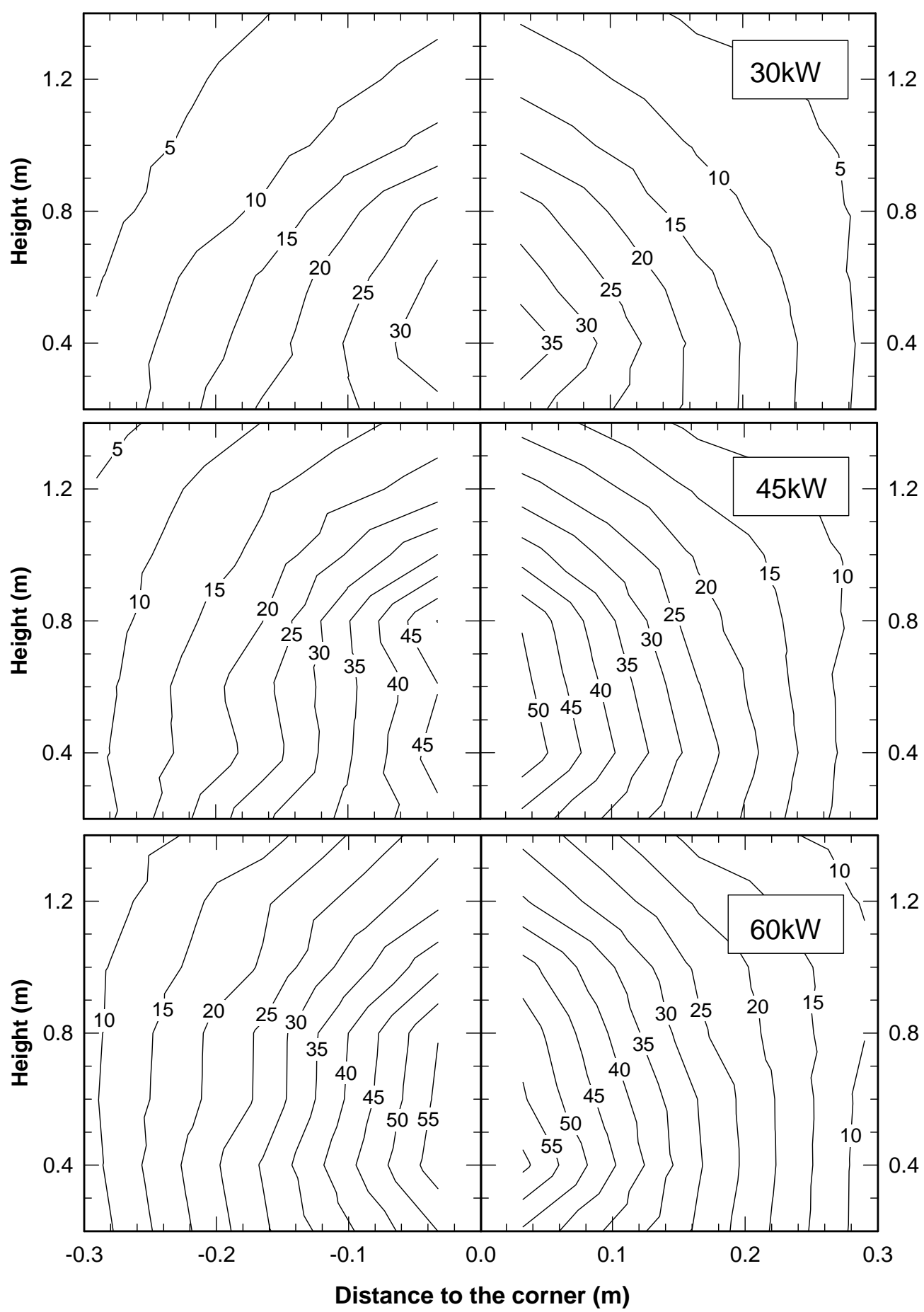

Fig. 4. Distributions of the derived surface heat flux on the left (left) and right (right) panels at different HRRs. X, Y coordinates are not in scale for illustration purpose.

\section{Determined flame heights}

The videos recorded were a succession of images taken at the rate of 25 images per second. Therefore, each video contains about $25 \times 180$ (4500) images. Because of the turbulent nature of the flame the instantaneous flame height fluctuates considerably. An image processing technique based on the flame presence probability [11] was used to determine the mean flame height. For each test, 180 images were randomly 
selected, and a flame height was obtained for each image. For any measured flame height, a probability is related to it. In this case, a total number of 180 images (denoted by $N$ ) were analyzed for each test, thus every instantaneous flame height has a probability equal to $1 / N$. After sorting the instantaneous flame height in an ascending order, a cumulative curve was created. The result for one of the tests at $45 \mathrm{~kW}$ is presented in Fig. 5, plotting the intermittency (denoted by $I$ ) as a function of the flame height $\left(H_{f}\right)$, where we have adopted Zukoski's criterions for the definitions of the maximum flame height $(I=0.05)$, mean flame height $(I=0.5)$ and continuous flame height $(I=0.95)$ [13].

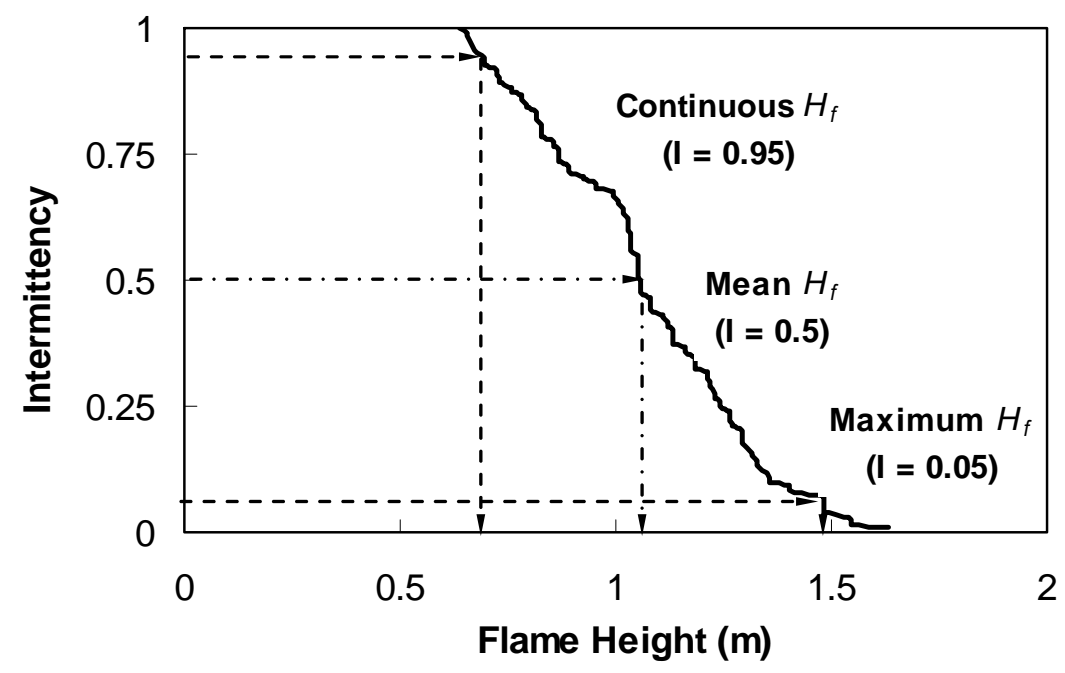

Fig. 5. Experimentally determined intermittency against flame height for a test at $45 \mathrm{~kW}$.

By applying the above technique to the images at all the HRRs, the continuous, mean and maximum flame heights are plotted in Fig. 6 as a function of the HRR. The flame heights increase with the HRR as expected. The mean flame heights at 30,45 , and $60 \mathrm{~kW}$ are about $0.8,1$ and $1.25 \mathrm{~m}$ respectively. These results are consistent with the heat flux measurements in Fig. 4, where we note that these heights at different HRRs correspond to the surface heat fluxes from $25-30 \mathrm{~kW} / \mathrm{m}^{2}$.

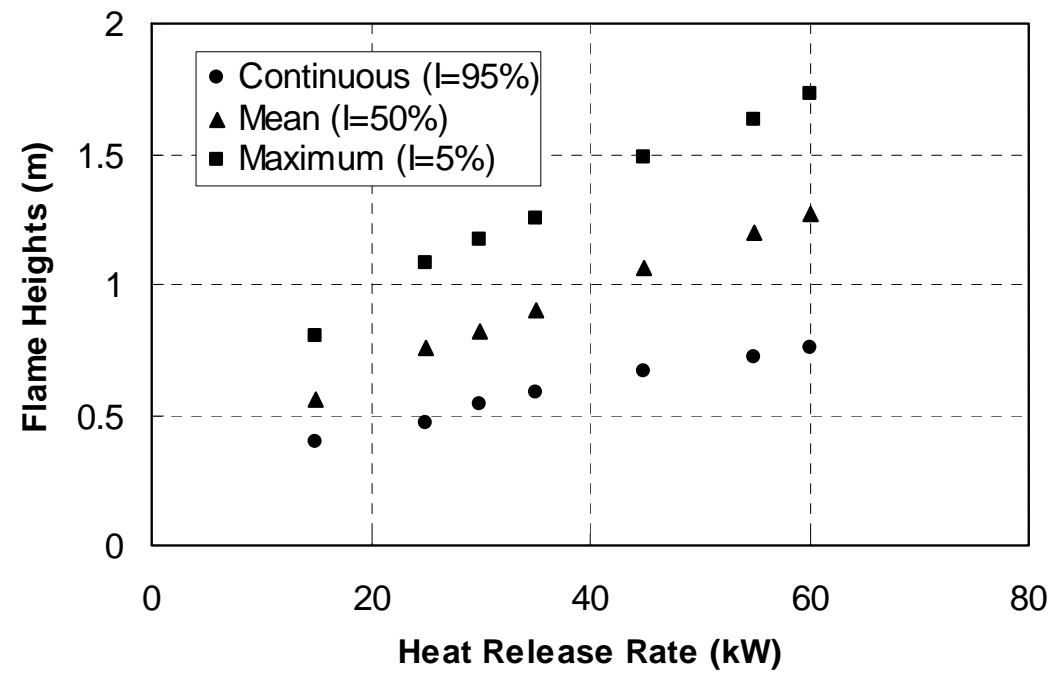

Fig. 6. Experimental continuous, mean and maximum flame heights at different HRRs.

\section{Dimensionless flame heights and heat fluxes}

The HRR can be expressed in its dimensionless form as: 
$\dot{Q}^{*}=\frac{\dot{Q}}{\rho_{a} c_{p} T_{a} \sqrt{g} D^{5 / 2}}$

where $\dot{Q}$ is the experimental HRR, $\rho_{a}$ the ambient air density, $c_{p}$ the specific heat of the ambient air, $T_{a}$ the ambient air temperature, $g$ the acceleration due to gravity, and $D$ the fire source diameter and in this study assumed to be the length of the shortest side of the burner equal to $0.25 \mathrm{~m}$.

In Fig. 7, the dimensionless mean flame height $\left(H_{f} / D\right)$ is plotted against $Q^{*}$, together with the correlations proposed by various researchers, i.e. $H_{f} / D=3.03 \dot{Q}^{* 0.9}$ by Kokkala [2], $H_{f} / D=3.65 \dot{Q}^{*^{2 / 3}}$ by Hasemi, and $H_{f} / D=-2.04+6.62 \dot{Q}^{* 2 / 5}$ by Heskestad [3]. A least squares fit to the dimensionless mean flame height gives: $H_{f} / D=3.886 \dot{Q}^{* 0.588}$, with a coefficient of confidence close to 1 . As shown in Fig. 7, the correlation derived in this work is closest to Hasemi's correlation, whereas Kokkala's correlation gives lower flame heights and Heskestad's correlation yields higher flame heights. It is worth pointing out that Heskestad's correlation was developed by assuming that a fire burning against a wall could be modeled as there was an identical imaginary fire source mirrored on the other side of the wall [3], or in the case of a corner fire the actual fire source was considered as one quarter of the total fire source (actual and imaginary). The flame height was then calculated based on the total fire source burning as an open fire. This method tends to overpredict the flame height as shown in Fig. 7.

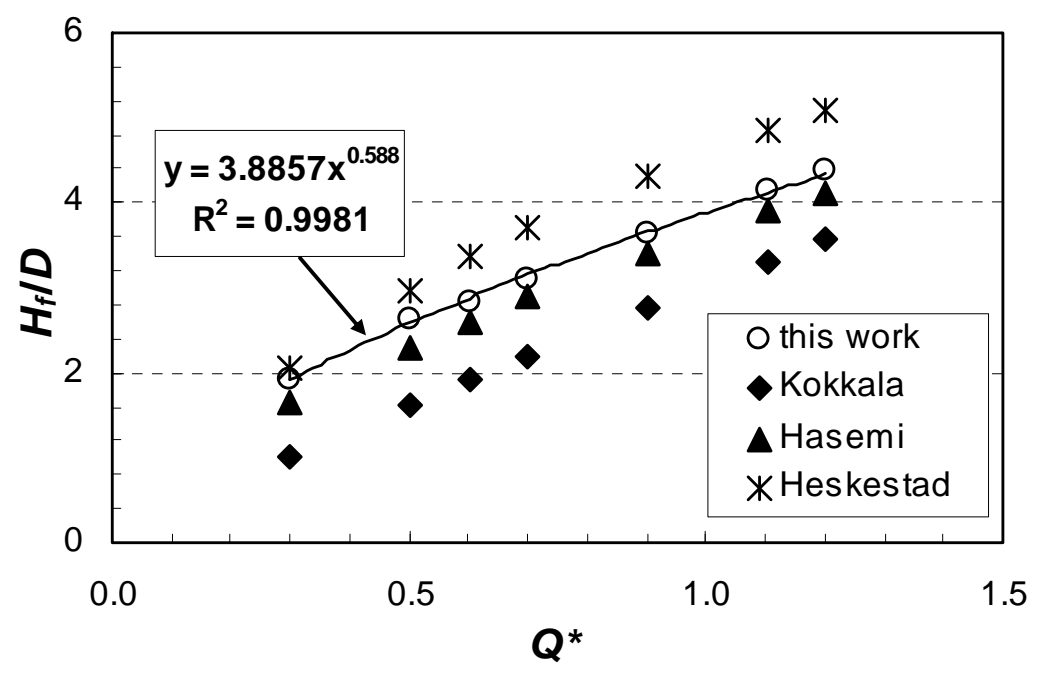

Fig. 7. Comparison of the dimensionless flame height $H_{f} / D$ as a function of the dimensionless HRR $Q^{*}$ derived in this work with correlations proposed by various researchers [1-3].

Figure 8 plots the dimensionless heat flux $\left(\left(q^{\prime \prime} H_{f} D\right) / \dot{Q}\right.$, where $q^{\prime \prime}$ represents the derived heat flux using the steel plate probes) against a dimensionless height $\left(Z / H_{f}\right)$, i.e. height $(Z)$ normalized by the flame height $\left(H_{f}\right)$, at different distances to the corner (i.e. 3.25, 16.5 and $29 \mathrm{~cm}$ ). The dimensionless heat flux appears to be weakly dependent on the HRR, and the maximum dimensionless heat fluxes are almost the same at different HRRs. The dimensionless heat flux at $29 \mathrm{~cm}$ (outside the flame region) is nearly constant, whilst those at 3.25 and $16.5 \mathrm{~cm}$ show an initial increase with height up to $Z / H_{f}=0.5$, and then decrease quickly with a further increase in height. 


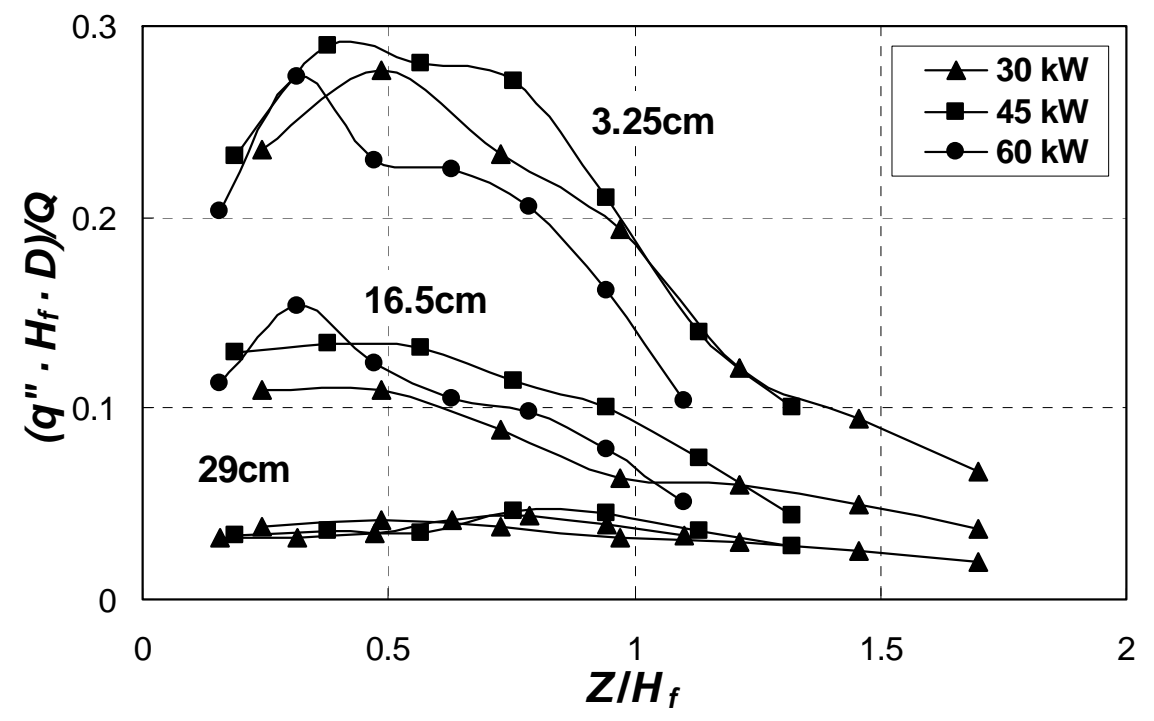

Fig. 8. Dimensionless heat flux $\left(q^{\prime \prime} H_{f} D\right) / \dot{Q}$ against dimensionless height $Z / H_{f}$. Texts $29 \mathrm{~cm}, 16 \mathrm{~cm}$ and $3.25 \mathrm{~cm}$ represent the distances from the steel plate probe trees to the corner.

\section{NUMERICAL MODELLING}

In FDS combustion is modeled with a mixture fraction concept and thermal radiation is computed using a finite volume technique on the same grid as the flow solver [12]. It employs the finite-difference method, with second-order explicit predictor-corrector time discretisation and second-order central difference space discretisation. The time-step is determined dynamically during calculations based on the local control volume size and velocity to ensure computational convergence.

In the present calculations, the whole domain $(3 \mathrm{~m} \times 3 \mathrm{~m} \times 2.4 \mathrm{~m})$ consisted of 1.2 million control volumes $(100 \mathrm{X} \times 100 \mathrm{Y} \times 120 \mathrm{Z})$ with local refinement in the flaming region, and the smallest grid size is $2 \mathrm{~cm}$. Grid sensitivity tests showed that further refinement of the grid size has negligible effect on the simulation results. A uniform velocity profile was imposed at the exhaustion duct based on the experimental volume flow rate having an average value about $0.5 \mathrm{~m}^{3} / \mathrm{s}$. Calculations were carried out on a FUJITSU SIEMENS PC with a $3.60 \mathrm{GHz}$ dual processor and 3GB of RAM. It took approximately 120 hours for a typical run of 100 seconds physical time. The calculation results presented in this section are the average values over the last 10 seconds of the simulations.

\section{Surface heat fluxes}

Figure 9 shows comparisons of the FDS predictions and measured heat fluxes on both panels at different HRRs. The agreement between the two set of data is reasonable at $30 \mathrm{~kW}$; however the error increases considerably at higher HRRs. At $60 \mathrm{~kW}$, the model underestimates the heat flux by up to $40 \%$. These differences could be attributed in part to the uncertainties of the steel plate probes in the experiments (upto $15 \%$ as discussed earlier), but more importantly to the accuracy of the sub-models in FDS. It is well known that the accuracy of combustion and radiation models has a paramount affect on the heat flux prediction. Although FDS provides a reliable flow solver, the mixture fraction combustion model could yield errors at large as $20 \%$ as suggested by the code developer [12] and the radiation model can not solve accurately the radiation equation with grid sizes in the order of centimeter due to the fourth power dependence of radiation on temperature. Furthermore, the assumption in FDS that the soot production is proportional to the local fuel burning rate would introduce errors in radiation calculations and in the prediction of gas temperature, and consequently in the prediction of the surface heat flux. 

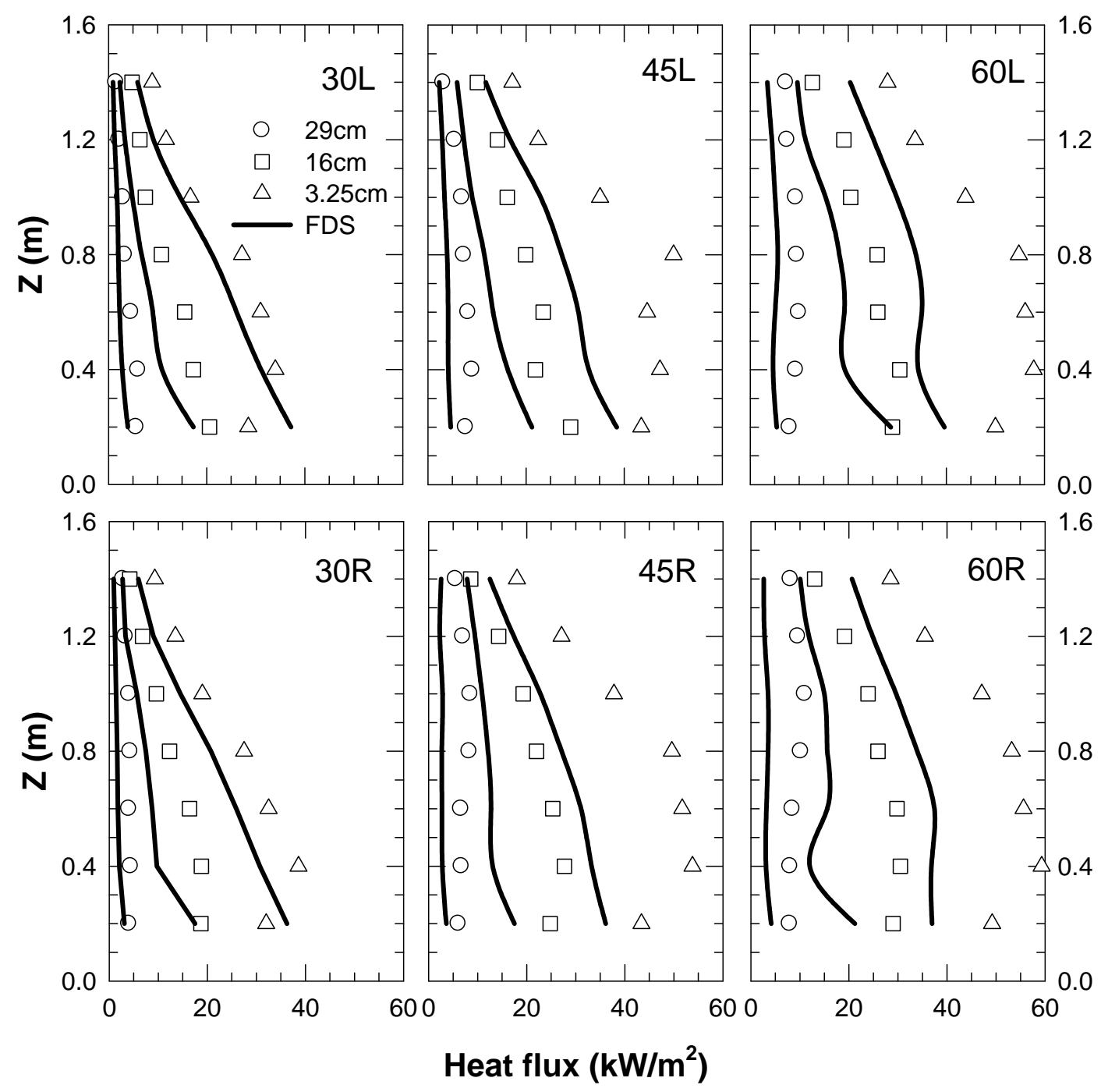

Fig. 9. Comparisons of the predictions and steel plate probe measurements. Captions 30, 45, 60 denote the HRR; L and R indicate the left and right panels respectively. In the legends, $29 \mathrm{~cm}, 16 \mathrm{~cm}$ and $3.25 \mathrm{~cm}$ represent the distances from steel plate probe trees to the corner.

\section{Flame heights}

In Table 2, the predicted flame heights at different HRRs, which were obtained by examining the isosurface of the local HRR [14], are compared to the experimental ones. In contrast to the underprediction of the surface heat flux, FDS predicts reasonably flame heights. However one should keep in mind that due to the turbulent nature of the flame the uncertainties are high in determining the flame heights in both experiments and calculations.

Table 2. Comparisons of the experimental and predicted flame heights at different HRRs.

\begin{tabular}{c|cc}
\hline HRR & Experiment $(\mathrm{m})$ & Prediction $(\mathrm{m})$ \\
\hline $30 \mathrm{~kW}$ & 0.8 & 0.9 \\
$45 \mathrm{~kW}$ & 1.0 & 1.2 \\
$60 \mathrm{~kW}$ & 1.25 & 1.4 \\
\hline
\end{tabular}




\section{Sensitivity of soot yield and radiative fraction in FDS}

In order to examine the sensitivity of the constant soot yield (denoted by Ys) used in FDS, its default value for propane (i.e. 0.01) has been modified to 0.05. Figure 10 shows the effect of Ys on the predictions of soot volume fraction and gas temperature at $60 \mathrm{~kW}$ (because FDS underpredicts the surface heat flux especially at higher HRRs as shown in Fig. 9). The vertical line is located $4 \mathrm{~cm}$ to both panels. The predicted soot volume fraction (fv) with a soot yield of 0.05 is about five times as that predicted with a value of 0.01 as expected and the maximum soot volume fraction found with Ys $=0.05$ is around 1.3ppm. Interestingly the predicted higher soot volume fraction with higher Ys appears to have little effect on the predicted temperature as one would expect since higher soot volume fraction would result in higher radiation losses and thus lower gas temperature. The insensitivity of the gas temperature on Ys could be attributed to the fact that in FDS a radiative fraction (denoted by RF) is used (default value for propane is 0.35). The actual radiation heat loss in a control volume is thus $\operatorname{Max}\left(\dot{q}_{f d s}, R F \times H R R\right)$, where $\dot{q}_{f d s}$ is the local radiation heat loss calculated by the radiation model in FDS, and HRR is the local heat release rate calculated by FDS. Use of the radiative fraction implies that even with a higher soot volume fraction if $\dot{q}_{f d s}$ is less than $R F \times H R R$, its value is neglected.
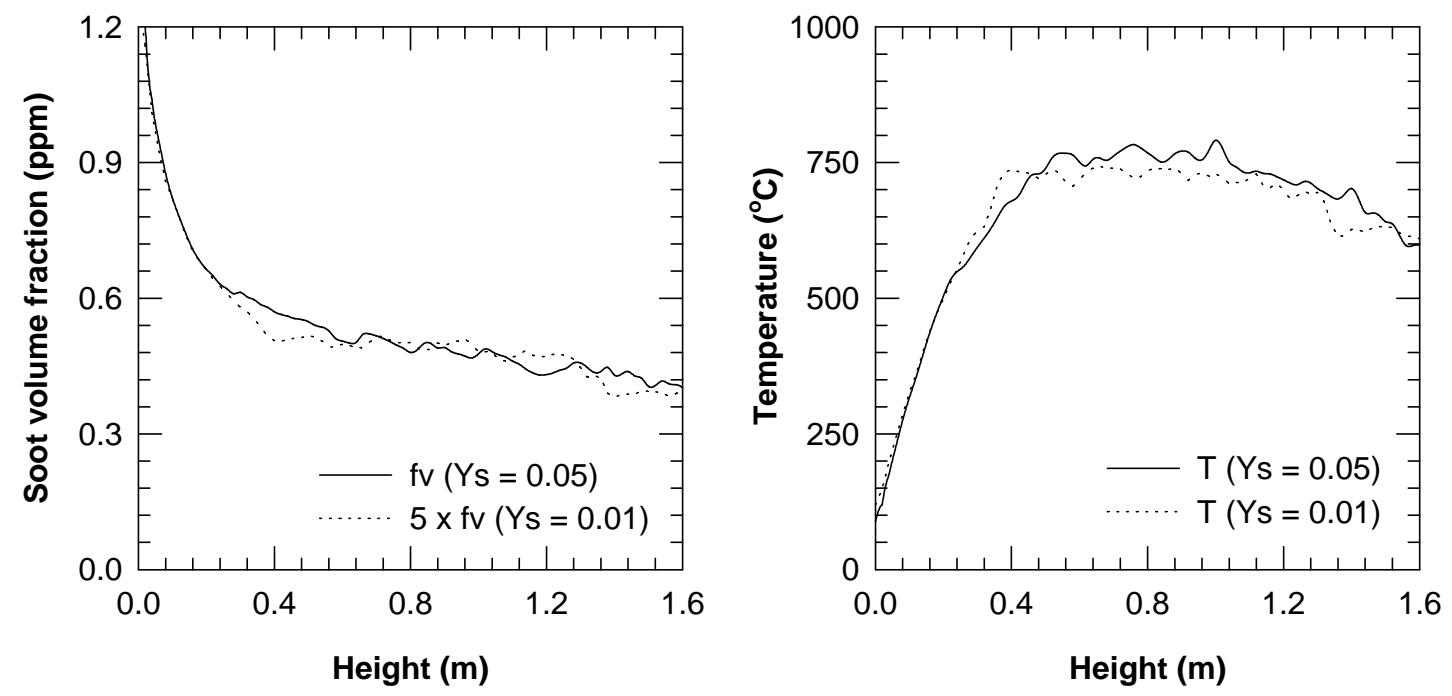

Fig. 10. Effect of soot yield on the predictions of soot volume fraction ( $\mathrm{fv}$ ) and gas temperature (T) at $60 \mathrm{~kW}$ ( $\mathrm{RF}=0.35$ in FDS). The vertical line is located $4 \mathrm{~cm}$ to both panels.

The combined effect of RF and Ys is shown in Fig. 11, which compares the predicted heat flux using different values of RF (0.0 and 0.35$)$ and Ys (0.01 and 0.05). The thermocouple tree is on the right panel and $3.25 \mathrm{~cm}$ to the corner. One clear observation is that use of the radiative fraction is essential for such applications since the predictions with $\mathrm{RF}=0.0$ and $\mathrm{Ys}=0.01$ (the results obtained using the radiation model in FDS) are significantly smaller than other simulation results and the experimental data. Another observation in Fig. 11 is that the predictions are closer to the measurements by increasing Ys, indicating the uncertainties in using a constant soot yield in FDS because the soot concentration could be larger inside the flames than the total yield outside. More accurate soot models are thus required on this note for applications where soot and radiation interaction is important. Recent efforts in this aspect include the work by Lautenberger et al. [15] and that by Beji et al. [16]. In [15], a semi-empirical model was developed involving polynomial fittings of the soot formation and oxidation rates, whereas the model in [16] was based on the soot formation rate from an analytical solution of a one-dimensional soot model using the smoke point height concept [17]. Both models have been implemented in FDS and validated against an experimental study of a laminar ethylene flame [18] and in general good agreements were found with the measurements in terms of soot volume fraction, gas temperature, and the flow field. However, in order to extend laminar soot models to turbulent cases for predictions of turbulent flames much work is still needed, which is currently being undertaken in the authors' group. 


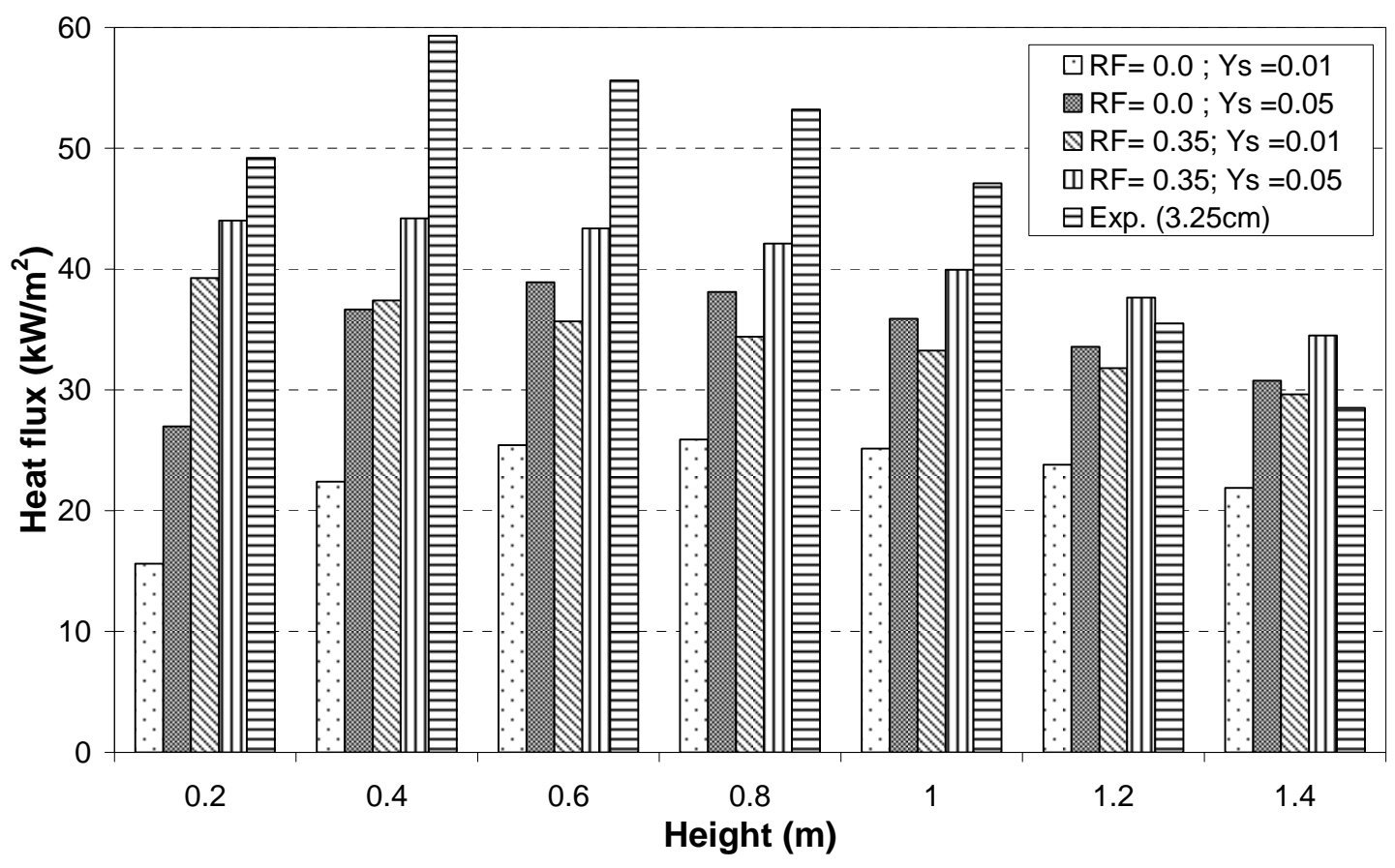

Fig. 11. Effect of radiative fraction (RF) and soot yield (Ys) on the prediction of the surface heat flux at $60 \mathrm{~kW}$. The radiation losses in the energy equation are calculated as $\operatorname{Max}\left(\dot{q}_{f d s}, R F \cdot H R R\right)$. The thermocouple tree is on the right panel and $3.25 \mathrm{~cm}$ to the corner.

\section{CONCLUSIONS}

Heat impact and flame heights from fires in the SBI tests were assessed by means of experiments and CFD simulations. Thin steel plate probes were used to measure the surface heat flux on inert walls, whereas a CCD camera was used to video-record the experiments, based on which flame heights were determined using an intermittency probability method. Experimental results were then used to assess the accuracy of the CFD code FDS for predictions of the surface heat flux and flame heights. The sensitivity of parameters in the radiation and soot models in FDS was also examined. The main conclusions of this work are:

- The surface heat flux in the SBI tests was found to remain relatively constant in the continuous flame region (see Fig. 8), and the maximum surface heat flux, which increases with the HRR, is found to be located about $40 \mathrm{~cm}$ above the burner for the three HRRs investigated;

- The flame height was found to increase with the HRR as expected; the correlation between the dimensionless flame height and HRR derived in this work agrees reasonably with literature findings;

- The accuracy of steel plate probes as a practical means for measuring the surface heat flux was demonstrated by comparison to Gardon gauge measurements in the cone and SBI tests, provided that the heating of the steel probe is fast (within few seconds). Note that in the cases where the heating is slow, steel plate probes can still be used to measure the steady heat fluxes by shielding the probes with inert boards prior to reaching the steady burning stage;

- FDS predicts reasonably the flame heights (see Table 2) but underpredicts significantly the surface heat flux (see Fig. 9). Sensitivity studies showed that: 1) use of the radiative fraction in FDS is essential for predictions in which the grid size is in the order of centimeter because the radiation model can not solve accurately the radiation equation due to the fourth power dependence of radiation on temperature, and 2) use of a constant soot yield to represent the soot production in FDS is inaccurate even though the effect of soot on radiation is attenuated by use of the radiative fraction, and more accurate soot models are required for predictions of soot production in applications where soot and radiation interaction is important. 


\section{ACKNOWLEDGEMENTS}

The authors wish to thank Mr. M. McKee and Mr. W. Veighey for helping with the experiments.

\section{REFERENCE}

[1] Hasemi, Y. and Tokunaga, T., (1984) Some experimental aspects of turbulent diffusion flames and buoyant plumes from fire sources against a wall out in a corner of walls, Combustion Science and Technology 4: 15-26,

[2] Kokkala, M.A., Characteristics of a flame in an open corner of walls, Interflam 1993.

[3] Heskestad, G., "Fire plumes”, SPFE Handbook of Fire Protection Engineering, 2nd Edition, 1995.

[4] Cheng, Q., “Turbulent flame spread on vertical corner walls,” National Institute of Standards and technology, NIST-GCR-95-669, 1995.

[5] Dillon, S.E., "Analysis of the ISO 9705 Room/Corner Test: Simulations, Correlations and Heat Flux Measurements, National Institute of Standards and Technology,” NIST-GCR-98-756, 1998.

[6] Ohlemiller, T.J., "Estimating Fire Growth on Composite Materials in a Corner Configuration," 45th International SAMPE Symposium and Exhibition 45, 2000, pp. 1229-1243.

[7] Lattimer, B.Y. and Sorathia, U., (2003) Thermal characteristics of fires in a non-combustible corner, Fire Safety Journal 38: 709-745, http://dx.doi.org/10.1016/S0379-7112(03)00065-1

[8] BRITISH STANDARD BS EN 13823:2002, Reaction to fire tests for building products Building products excluding floorings exposed to the thermal attack by a single burning item.

[9] Lennon, P.F. and Silcock, G.W.H., (2001) An investigation of the ability of a thin plate heat flux device to determine the incident heat fluxes during enclosure fires, International Journal of Engineering Performance-Based Codes 3: 1-15.

[10] Tofilo, P., "Factors controlling the behaviour of glazing systems in enclosures," PhD dissertation, University of Ulster, 2006.

[11] Audouin, L., Kolb, G., Torero, J.L. and Most, J.M., (1995) Average centreline temperatures of a buoyant pool fire obtained by image processing of video recordings, Fire Safety Journal 24: 167187, http://dx.doi.org/10.1016/0379-7112(95)00021-K

[12] McGrattan, K. and Forney, G., "Fire Dynamics Simulator (Version 4) User’s Guide,” NISR Special Publication 1019, 2005.

[13] Zukoski, E.E., Kubota, T. and Cetegen, B.M., (1981) Air entrainment in fire plumes, Fire Safety Journal 3: 107-121.

[14] Floyd, J. and Lattimer, B.Y., "Validation of FDS V4 boundary heat flux predictions for a corner fire,” Interflam 2003.

[15] Lautenberger C.W., de Ris, J., Dembsey N.A., Barnett, J.R. and Baum, H.R., (2005) A Simplified model for soot formation and oxidation in CFD simulation of non-premixed hydrocarbon flames, Fire Safety Journal 40: 141-176, http://dx.doi.org/10.1016/j.firesaf.2004.10.002

[16] Beji, T., Zhang, J. and Delichatsios, M.A., (2008) Determination of soot formation rate from laminar smoke point measurements, Combust. Sci. Technol. 180:927-940, doi:10.1080/00102200801894398

[17] Delichatsios, M.A., (1994) A Phenomenological Model for Smoke-Point and Soot Formation in Laminar Flames, Combust. Sci. Technol. 100: 283-298, doi:10.1080/00102209408935457

[18] Smyth, KC., "Diffusion flame measurements of species concentrations, soot concentrations, temperature, and velocity,” 1999. (Available online at http://www.fire.nist.gov/fire/flamedata/) 